\title{
Fibrin Glue Used as an Adhesive Agent in CNS Tissues
}

\author{
Henrich Cheng ${ }^{1,2}$, Susanne Almström ${ }^{1}$ and Lars Olson ${ }^{1}$ \\ ${ }^{I}$ Department of Neuroscience, Karolinska Institute, Stockholm, Sweden \\ ${ }^{2}$ Department of Neurosurgery, Neurologic Institute, Veteran General Hospital-Taipei \\ and Division of Surgery, National Yang-Ming Medical College, Taiwan, R.O.C.
}

\section{SUMMARY}

One of the limitations of many bridging experiments in neural transplantation is that the CNS tissues cannot be sutured. Fibrin glue is a two-component system derived from whole blood which, when mixed, reproduces the final stage of blood coagulation and solidifies. Many experimental studies of humans and animals show that fibrin glue repair of peripheral nerves is almost equivalent to microsurgical sutures. In this study, we attempted to extend its use to CNS tissues and transplants. Two techniques were tried: (1) Bilateral parietal knife cuts were performed by stereotaxic technique in six rats. Fibrin glue was applied in the right-side cortical lesion. Immunohistochemistry using antisera to tyrosine hydroxylase (TH), glial fibrillary acidic protein (GFAP), laminin and neurofilament (NF) was essentially similar between the control and treatment groups. The immunoreactivity of each marker revealed no significant differences between the two groups on days 1,7 and 30 . There was no difference in terms of gliosis or microvascular proliferation. (2) Embryonic day 16 fetal locus coeruleus was grafted together with E16 cortex to the anterior chamber of sympathectomized eyes. In the six eyes of the glue treatment group, the parietal cortical piece and the locus coeruleus piece were joined together before grafting by immersing them in the solution of fibrin glue. In the eight eyes of the control group, pieces of parietal cortex and locus coeruleus were introduced individually and approximated by gently pressing the cornea. The

Reprint address:

Henrich Cheng, M.D.

Histology, Department of Neuroscience

Karolinska Institute

S-171 77 Stockholm, Sweden sizes of double grafts showed no significant difference between groups during six weeks postgrafting. The immunohistochemical pictures using antisera against TH, GFAP and laminin were similar in both groups. Catecholaminergic fibers from the grafted locus coeruleus were found bridging over into the parietal cortical piece in both the control and treatment groups. There was no significant difference in THpositive nerve fiber density between tissue gluejoined and control double intraocular grafts. In conclusion, fibrin glue can be used as an adhesive agent in CNS tissues without hampering the outgrowth of neurites or causing adverse tissue reactions in fetal or adult nervous tissues.

\section{KEY WORDS}

fibrin glue, CNS repair, brain development, transplantation, locus coeruleus, cortex cerebri

\section{INTRODUCTION}

In the intensive search for methods to improve the regenerative capability of CNS tissues, many different bridging models have been attempted. One of the limitations of such experiments is that CNS tissues cannot be sutured. The CNS microvasculature cannot sustain suturing and the fragility of the tissue makes attempts to use stitches hazardous or useless. One approach uses transplants which may serve as bridges for regenerating axons across a site of injury $/ 25 \%$. Alternative methods for bridging by inserting peripheral nerve pieces, or lodging tissues into the CNS, or anchoring to the dura matter with microsutures could provide moderate but not strong joining.

For peripheral nerve repair, several sutureless methods have been developed, including fibrin glue 
and laser coaptations $/ 6,8,10-12,14,22,26 /$. Fibrin glue, or tissue glue, is a two-component system derived from whole blood which, when mixed, reproduces the final stage of blood coagulation to form a viscous adhesive. This glue is commercially available and used both clinically and experimentally in Europe and Japan. It consists of highly concentrated human fibrinogen which, after adding aprotinin, reacts with the calcium-activated thrombin to form a sealant that can maintain tissue approximation. Most of the experimental studies on humans or animals have shown that fibrin glue repair of peripheral nerves was equivalent to microsurgical sutures $/ 15,23,27 /$. Its major advantage over sutures is that the time required for the procedure is shorter and the anastomosis is easier to perform, especially in hard-to-access areas.

In this study, we attempted to extend the use of fibrin glue to CNS tissues and transplants. First, a rodent CNS lesion model was used to evaluate any adverse effect of the glue in lesioned CNS areas. Next, we used the fibrin glue as an adhesive agent between two pieces of intraocular fetal grafts (locus coeruleus and cerebral cortex) to evaluate its influence on survival and growth of fetal tissue grafts. Finally, the intraocular double graft model allowed us to determine whether nerve fibers could bridge a layer of fibrin glue at the interface between two brain tissue areas.

\section{MATERIALS AND METHODS}

\section{Fibrin glue}

The fibrin glue used for the present study was a fibrinogen-based compound with double sealant components (Beriplast ${ }^{\mathbb{}} \mathrm{P}$, Behring, Behringwerke AG, Marburg, Germany). The $1 \mathrm{ml}$ Beriplast ${ }^{\circledR} \mathrm{P}$ set contains:

Vial 1: Fibrinogen concentrate consisting of 115$232 \mathrm{mg}$ dry substance, containing a human plasma protein fraction with $65-115 \mathrm{mg}$ fibrinogen and a human plasma protein fraction with a factor XIII activity of 40-80 U.

Vial 2: Aprotinin solution consisting of $1 \mathrm{ml}$ solution containing $1000 \mathrm{KIU}$ of bovine lung aprotinin. Vial 3: Thrombin consisting of 4.9-11.1 mg dry substance containing a human plasma protein fraction with a thrombin activity of 400-600 IU.

Vial 4: Calcium chloride solution consisting of 2.5 $\mathrm{ml}$ solution containing $14.7 \mathrm{mg}$ calcium chloride $2 \mathrm{H}_{2} \mathrm{O}(40 \mathrm{mmol} / \mathrm{l})$.

Before application, the two sealant elements were prepared separately by transferring the aprotinin solution to the fibrinogen concentrate and transferring the calcium chloride solution to the thrombin. To apply the fibrin glue, a tuberculin syringe was filled with each sealant element. By pushing the two syringe plungers simultaneously, a coagulating glue forms between the tips.

\section{Fibrin glue in a CNS lesion model}

Adult 150-g female rats (Sprague-Dawley, B\&K Universal, Stockholm) were used to study the effect of fibrin glue in the CNS lesion model. Under general halothane anesthesia, the animal was mounted in a stereotaxic frame. A sharp blade with a flat cutting edge, $2 \mathrm{~mm}$ in length, was clamped onto the frame. Bilateral parietal craniectomies were performed to expose $3 \times 3 \mathrm{~mm}^{2}$ areas on both sides. The central bony ridge over the sagittal sinus was preserved to impede the liquid flow from one side to the other. Under stereotaxic guidance, the centers of the craniectomies were identified for cortical incision (AP 1.5, L/R 1.5, V 0 from bregma). The dura was opened and bilateral cortical incisions were performed by moving the clamped blade $3 \mathrm{~mm}$ downward (from V 0 to $\mathrm{V} \mathrm{3}$, see Fig. 1). The confronting vessels on the cortical surface were cauterized and severed before cutting to prevent profuse bleeding. Fibrin glue was applied into the right-side cortical lesion. Care was taken to avoid any fluid leak to the left side. After the glue hardened, the craniectomies were covered by pieces of spongostan and the wound closed.

The six rats were grouped into three groups and sacrificed on days 1,7 and 28 respectively. The animals were anesthetized with sodium pentobarbital (Mebumal $40 \mathrm{mg} / \mathrm{kg}$ i.p.) and perfused via the ascending aorta with $50 \mathrm{ml}$ calcium-free Tyrode's solution followed by $50 \mathrm{ml}$ formalin-picric acid mixture (4\% paraformaldehyde, $0.4 \%$ picric acid in $0.16 \mathrm{M}$ phosphate buffer, $\mathrm{pH}$ 7.4). Brains were removed and processed for indirect immunohistochemistry using antibodies against tyrosine hydro- 


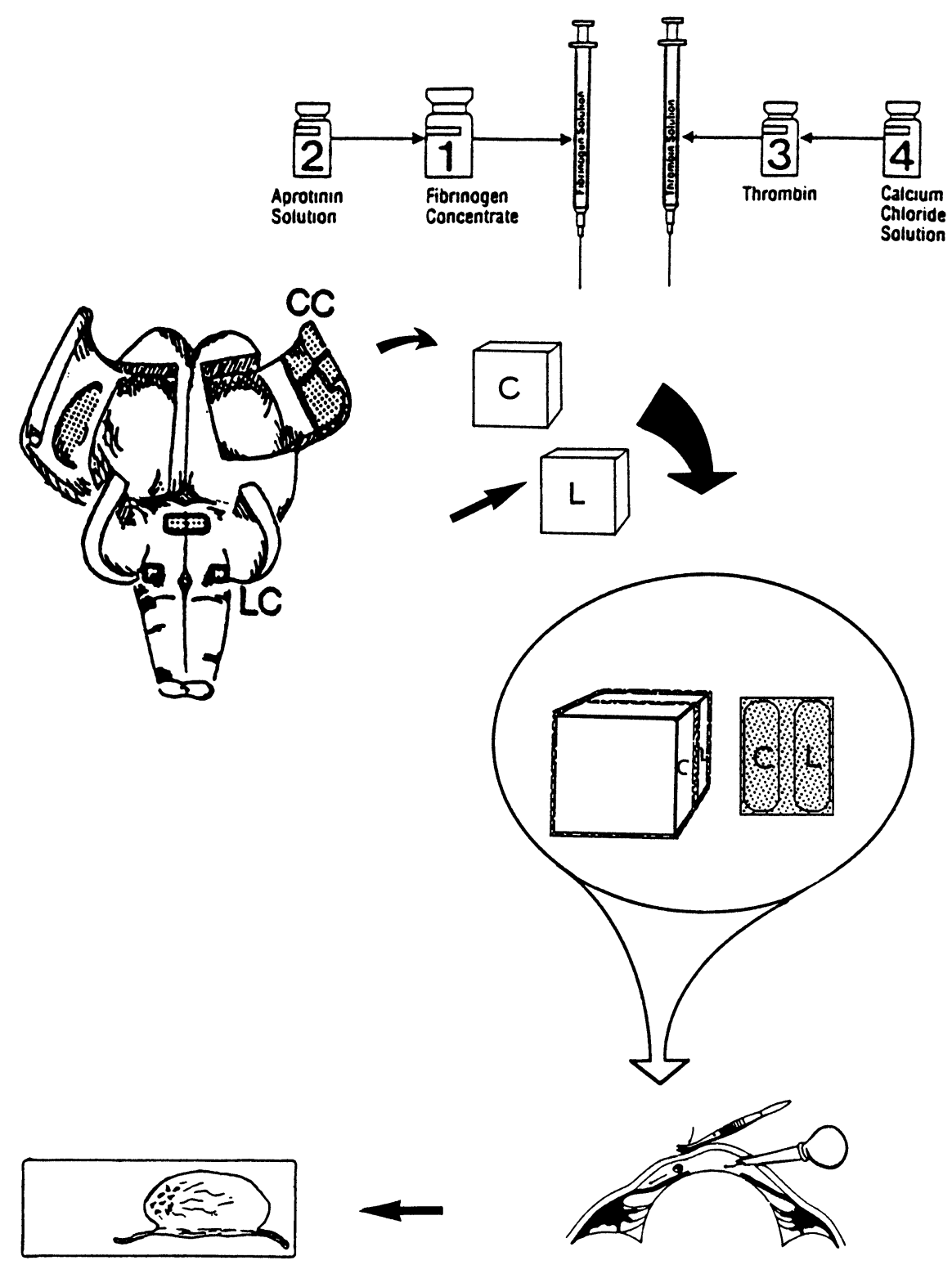

Fig. 1: Schematic diagram illustrating the procedures for double intraocular grafts. Pieces of parietal cortex (CC) and locus coeruleus (LC) were dissected out from the E16 fetal brain. In the treatment group, a cortical piece and a locus coeruleus piece were joined together by immersing them in the unhardened solution of fibrin glue. The glue-joined double grafts were introduced into the anterior chambers of sympathectomized eyes. Six weeks later, the grafts were removed for immunohistochemical examination. C: parietal cortical piece, L: locus coeruleus piece.

xylase (TH), glial fibrillary acidic protein (GFAP), laminin, and neurofilament protein (NF). Tissues were examined and photographed using epifluorescence microscopy (Nikon-Microphot). Densities of TH, GFAP, laminin and NF immunoreactivities were semiquantitatively scored on all sections. Averages from 6-10 sections from a given brain were then calculated. A semiquantitative scale from 0-5 was used.
Fibrin glue in double intraocular grafts (locus coeruleus + cortex cerebri)

Young adult 150-g female rats (SpragueDawley, B\&K Universal, Stockholm) were used as hosts to study the effect of fibrin glue in double intraocular grafts. All eyes were sympathetically denervated by superior cervical ganglionectomy one week before transplantation. Fetuses from pregnant 

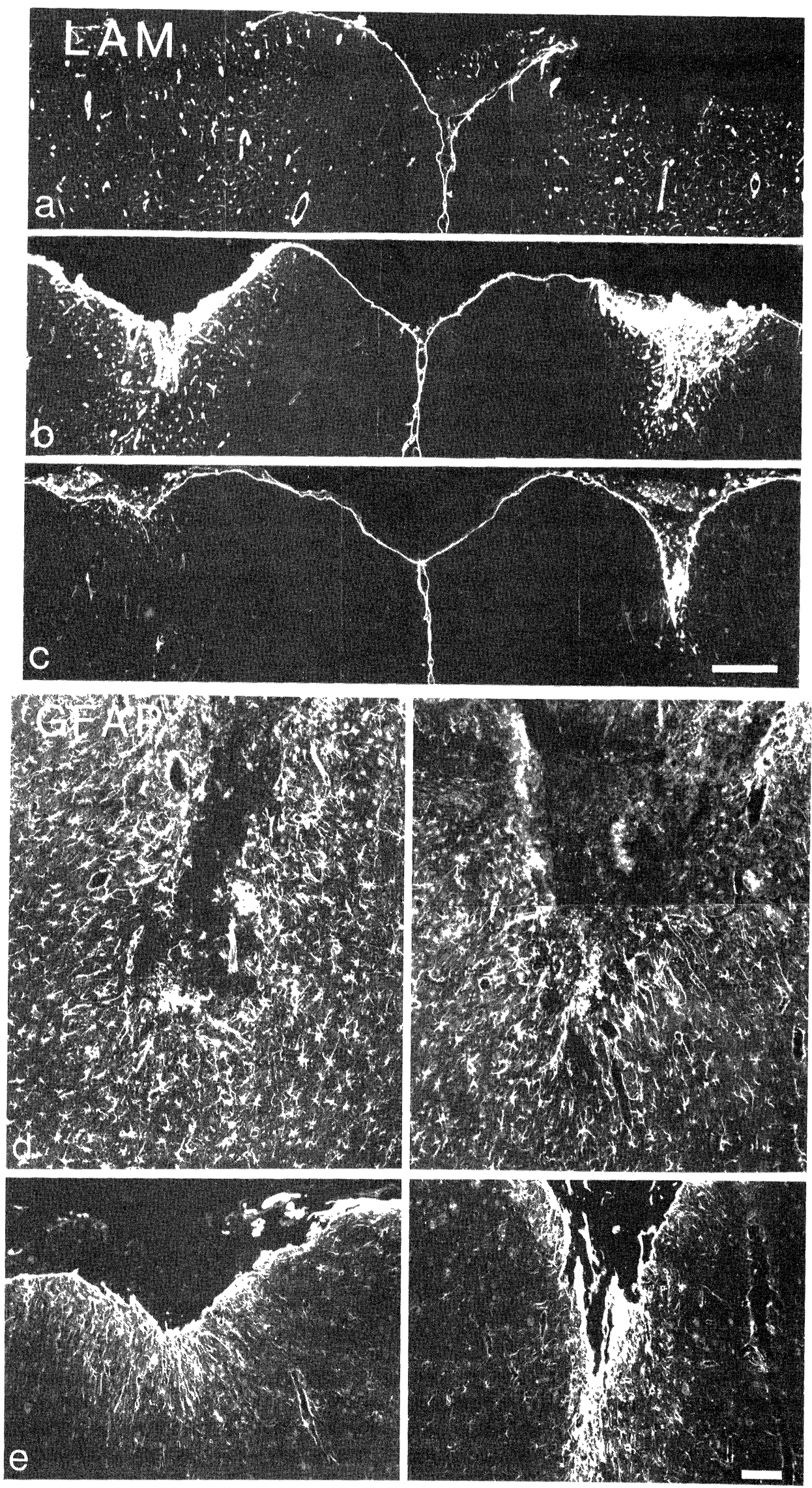

JOURNAL OF NEURAL TRANSPLANTATION \& PLASTICITY 

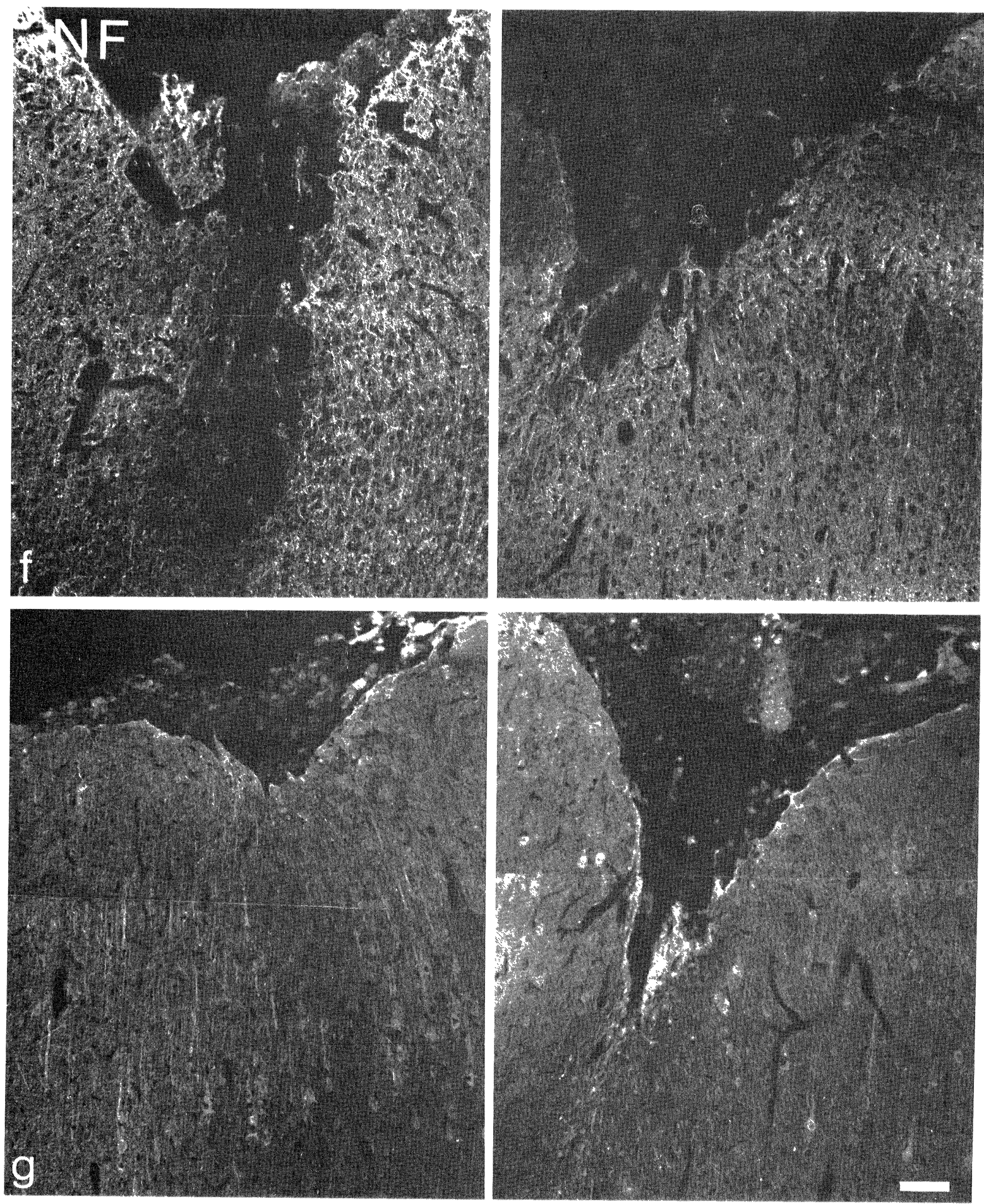

Fig. 2: Immunohistochemistry of lesioned cerebral cortices on days 1, 7 and 30. The histologic pictures with four different immunoreactive markers were similar between the control (right side) and the glue-treated (left side) cortices. GFAP: glial fibrillary acidic protein, LAM: laminin, NF: neurofilament protein, TH: tyrosine hydroxylase. a: day $1 ; \mathrm{b}, \mathrm{d}$ and $\mathrm{f}$ : day 7;c,e and g: day 30. Scale bar $=500 \mu \mathrm{m}$ in LAM. Scale bar $=100 \mu \mathrm{m}$ in GFAP and NF. 
rats of the same strain were used as donors of CNS tissue grafts. Pieces of parietal cortex and locus coeruleus from E16 fetal brains were dissected out. In the treatment group, the cortical and locus coeruleus pieces were joined together by immersing them in the fibrin glue solution. The superfluous glue around the joined piece was trimmed after the glue had hardened. After pretreatment of all eyes with a drop of $1 \%$ atropine solution, intraocular grafting was performed under ether anesthesia. Grafts were introduced through a tiny opening of the cornea as previously described /19-21/ using a modified Pasteur pipette. The fibrin glue-treated combined graft was introduced as a single piece, while in the control group pieces of parietal cortex and locus coeruleus were introduced individually and juxtaposed by gentle pressure on the cornea. After grafting, the volumes of the transplants were measured at regular intervals by stereomicroscopy. The graft size was estimated by taking the longest diameter of the graft multiplied by the diameter perpendicular to it $/ 4 /$. Eleven animals were used which consisted of six eyes in the treated group, eight eyes in the untreated group and six eyes of cortico-cortical glue-treated double grafts as negative controls (see Fig. 1).

The animals were perfused six weeks after grafting using procedures as stated above and processed with the same methods for indirect immunohistochemistry using antibodies against $\mathrm{TH}$, GFAP and laminin. Scoring of TH-immunoreactive nerve fiber density, GFAP-like, and laminin immunoreactivities was performed on all sections. Averages from 6-10 sections from a given graft were then calculated to generate means of $\mathrm{TH}$ immunoreactive nerve fiber density, GFAP-like and laminin immunoreactivity per section. A semiquantitative scale from 0-5 was used.

\section{Statistical analysis}

\section{Fibrin glue in CNS lesion model}

The data were analyzed by nonparametric MannWhitney tests. Within each group, the data from the immunoreactivity of glue-applied sides were compared with the data from the corresponding immunoreactivity of control sides.
Fibrin glue in double intraocular grafts (locus coeruleus + cortex cerebri)

Graft sizes were analyzed by single-factor repeated measures ANOVA test. The univariate analysis was based on repeated measurements on the same rats. Number of days after surgery and number of eyes were treated as within-subject factors. Rats were grouped within the treatment groups. The type of treatment was a betweensubject factor. The measurements of TH-immunoreactive nerve fiber density, GFAP-like and laminin immunoreactivity were analyzed by ANOVA.

\section{RESULTS}

\section{Fibrin glue in CNS lesion model}

The right parietal cortex cuts which received fibrin glue were compared with the left parietal cortices that received lesions only. The patterns of immunohistochemistry using antisera against $\mathrm{TH}$, GFAP, laminin and NF were similar between the control and treatment groups on days 1, 7 and 30 (Fig. 2). There was no difference in the degree of gliosis or microvascular proliferation. No morphologic evidence of any special tissue reaction could be found in the treatment group. Using the semiquantitative data, none of the immunoreactive markers revealed in the glue group differed significantly from the controls on days 1,7 or 30 (Fig. 3).

Fibrin glue in double intraocular grafts (locus coeruleus + cortex cerebri)

\section{Growth of double intraocular grafts}

With or without fibrin glue, joined fetal (E16) locus coeruleus and cortex cerebri double pieces were grafted to the anterior chamber of the eye of sympathetically denervated host rats. All but two of the grafts (in the group of cortico-cortical grafts) survived well and became vascularized from the host iris. As shown in Fig. 4, there was no significant difference in volume change between the gluetreated and untreated locus coeruleus plus cortex cerebri grafts $(P=0.25$ on day $5, P=0.38$ on day 14 , and $P=0.52$ on day 25 , ANOVA). 

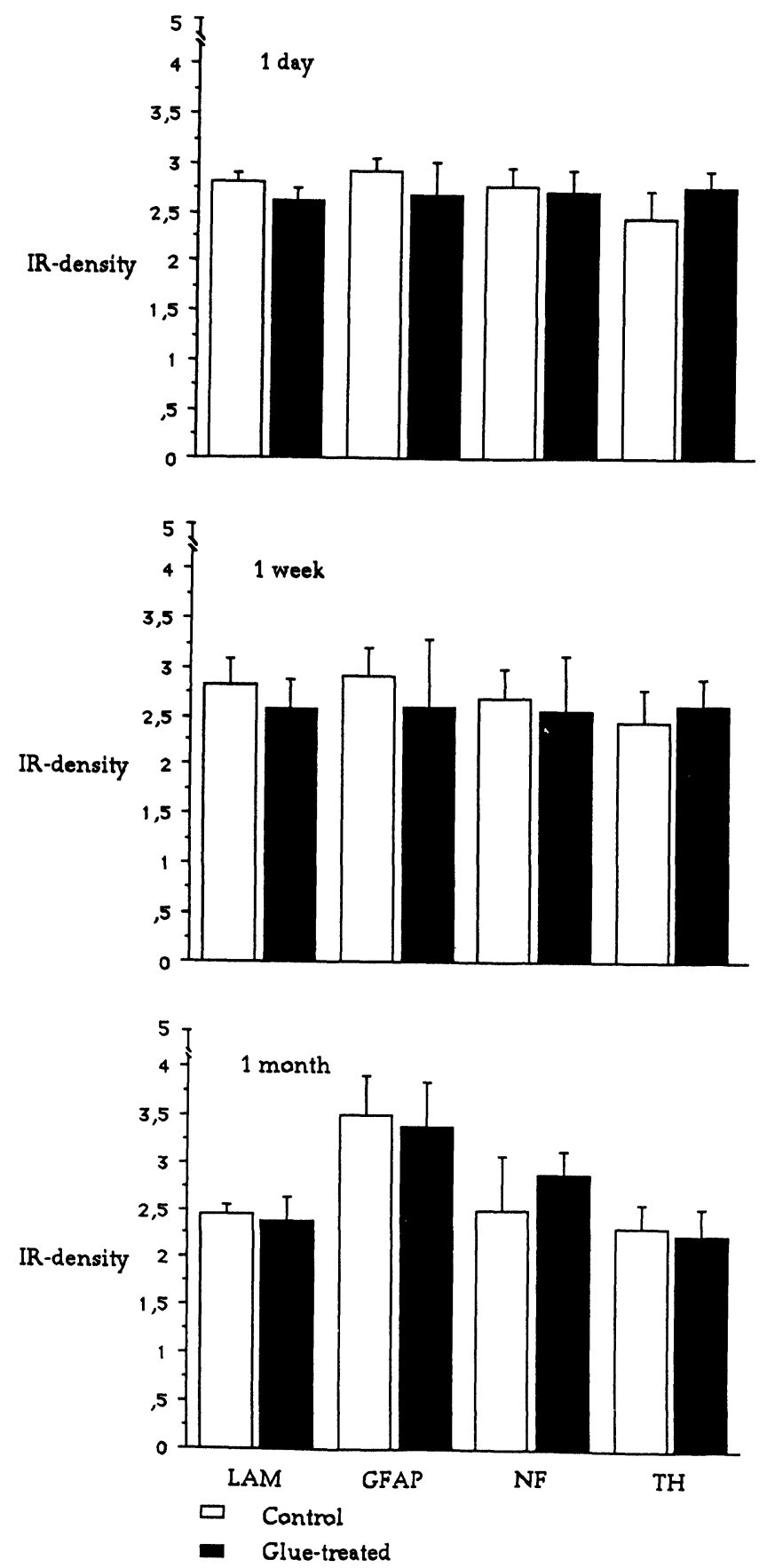

Fig. 3: Comparison of the immunoreactivity between gluetreated and control lesioned cortex with four immunohistochemical markers based on 6-10 serial sections from each brain ( $n=2$ for each group). The density of neural, glial and vascular elements with four immunohistochemical stains was similar in the glue-treated and control lesioned cortex on days 1,7 and 30 . The fiber density of each section was graded from 0 to 5. LAM: laminin, GFAP: glial fibrillary acidic protein, NF: neurofilament protein, TH: tyrosine hydroxylase.

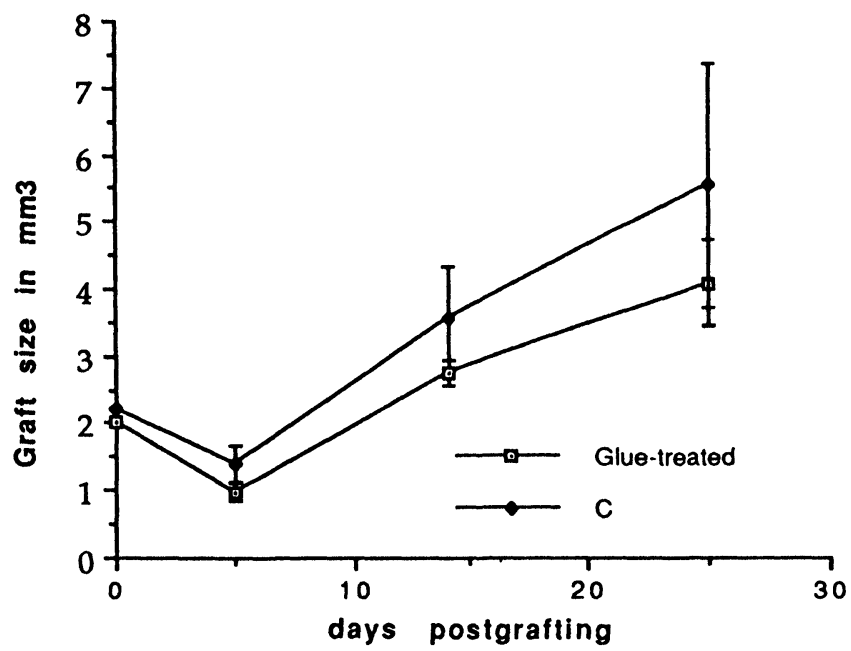

Fig. 4: Volume of double intraocular grafts (locus coeruleus + cortex cerebri, E16) on days 5, 14 and 25 . No significant difference in volume change was noted between the glue-treated and untreated locus coeruleus plus cortex cerebri grafts (glue-treated double grafts, $n=6$; untreated controls, $n=8$; ANOVA).

Effects of fibrin glue on TH-positive nerve fiber density, GFAP and laminin immunoreactivity in intraocular double grafts

The catecholaminergic fibers in the intraocular double grafts were examined using TH immunohistochemistry. There was no significant difference in TH-positive nerve fiber density between gluejoined and untreated locus coeruleus plus cortex cerebri grafts (Figs. 5, 6; $\mathrm{P}=0.76$, ANOVA). Comparing the TH-positive fiber density in the above glue-treated or untreated locus coeruleus plus cortex cerebri grafts with the glue-treated cortico-cortical grafts, significant differences were noted ( $P=0.017$ for the untreated and corticocortical grafts, $P=0.01$ for the glue treated and cortico-cortical grafts, ANOVA; Fig. 5). Studies of GFAP and laminin immunoreactivity in the grafts revealed no obvious differences between the different treatments (see also Fig. 5).

\section{DISCUSSION}

The fact that no morphologic difference could be found between the fibrin glue-treated and control lesioned cortex suggests that fibrin glue does not produce harmful effects in CNS tissue. Gliosis and 


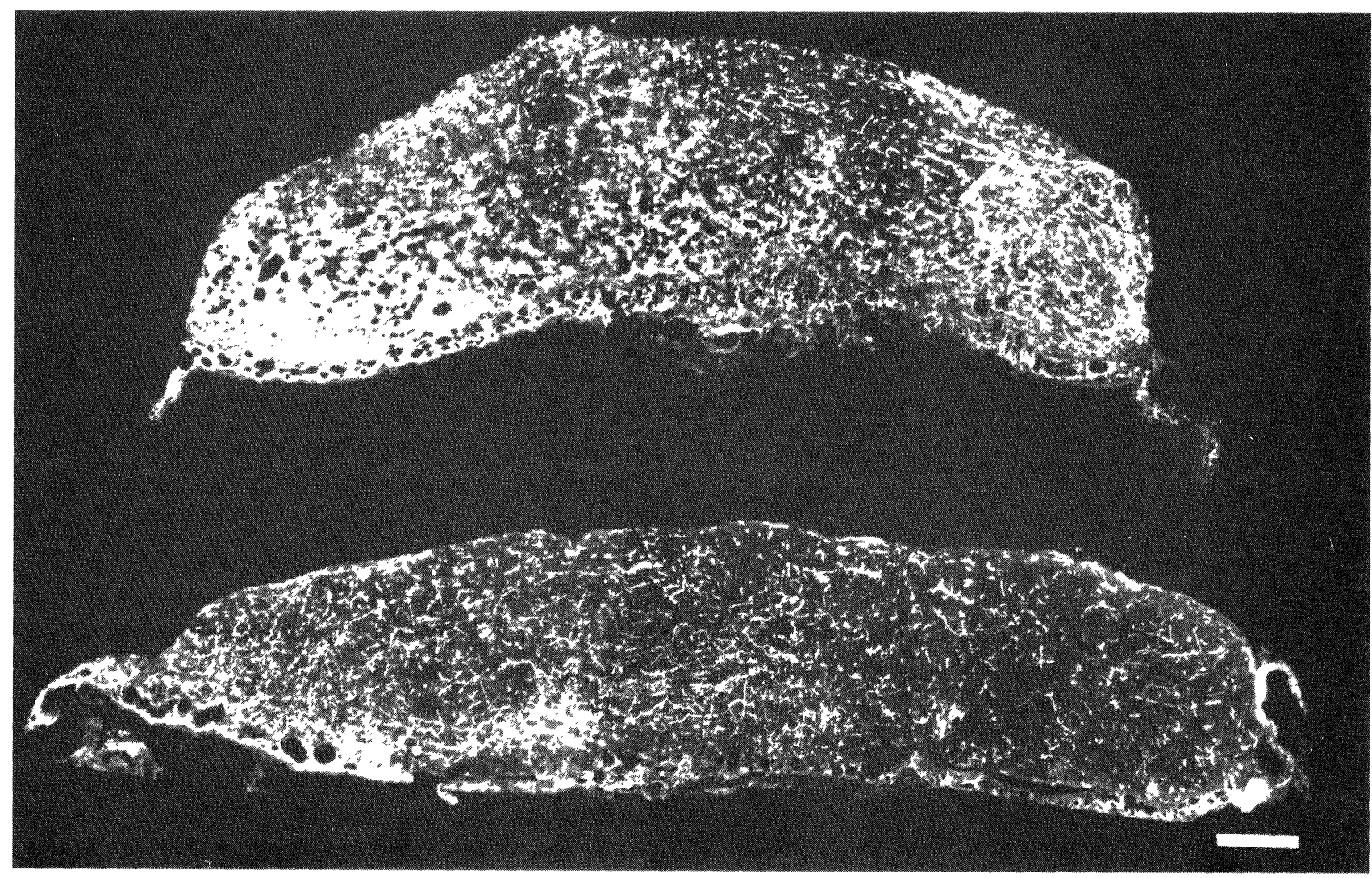

Fig. 5: Immunohistochemistry of double intraocular grafts 37 days postgrafting. The TH-positive nerve fiber density was similar between glue-joined (upper) and untreated (lower) locus coeruleus plus cortex cerebri grafts. Scale bar $=200$ $\mu \mathrm{m}$.

microvascular proliferation did not increase in the glue-treated lesioned cortices in the early, intermediate or late periods after injury. Studies of TH and NF immunoreactivity also indicated that neural components of the CNS tissue are unaltered after the application of glue. As shown by many authors $/ 1-3,8-11,13,14,16,22,24,26,28 /$, fibrin glue produces no adverse tissue reaction in PNS tissues. After axotomy, axons can penetrate the glue region and grow in the distal stumps.

The major controversy concerning the application of fibrin glue in peripheral nerve repair is whether it can replace the conventional microsuture technique. Studies by several authors $/ 3,9,10,14,22 /$ have shown that the effect of fibrin glue in nerve coaptation is comparable to microsutures in tensile strength, regenerative axonal counts and, although slower in conduction velocity, electrophysiologic responses. The advantages of fibrin glue in surgery are rapidity of application, good hemostasis, easier stabilization of small grafts and possibility of anastomosis in some difficult anatomical positions $/ 8,15,22 /$. The disadvantage of possible bacteria and virus transmission has been resolved by inactivation. Screening for hepatitis B antibodies since the early 1980s and for AIDS virus antibodies since the 1990s has been done to scrutinize both source material and the final product $/ 15 /$. With a relatively aseptic technique, as presented in this study, infection is not a problem with the use of fibrin glue in the CNS tissues.

The vulnerable nature of the microvasculature of CNS tissue, the fragile texture of the parenchyma and the sophisticated neural networks combine to make suturing impossible for reparative intervention. The present intraocular double grafting experiments have demonstrated a possible role for fibrin glue to act as a CNS adhesive agent to glue CNS tissues together. The glue-joined fetal double grafts survived and grew on the iris. Statistical 


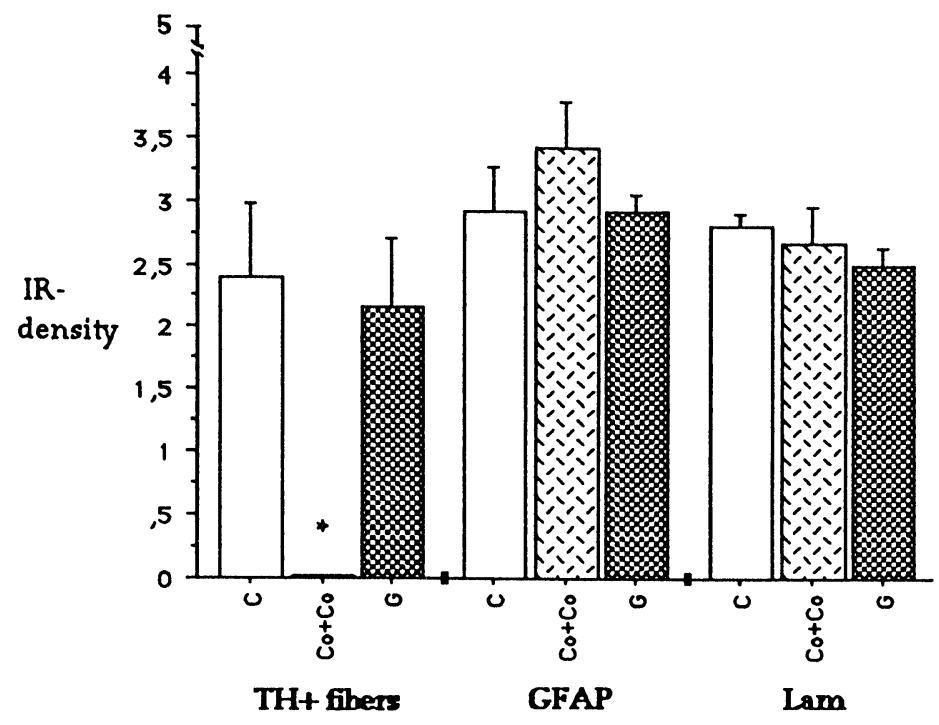

Fig. 6: Comparison of TH-positive nerve fiber density, GFAP-like and laminin immunoreactivity between glue-joined double intraocular grafts (G: locus coeruleus + cortex cerebri, E16, n=6) and untreated double intraocular grafts (C: locus coeruleus + cortex cerebri in HBSS, E16, $n=8$ ). Double pieces of cortex cerebri $(\mathrm{Co}+\mathrm{Co}$ : cortex cerebri + cortex cerebri, E16, $n=4$ ), joined by fibrin glue, were also used as negative controls. There is no significant difference in TH-positive nerve fiber density between tissue glue-joined and untreated double intraocular grafts. Significant differences are noted between the above two groups and the corticocortical grafts $(\mathrm{P}=0.0165$ for $\mathrm{C} ; \mathrm{Co}+\mathrm{Co}, \mathrm{P}=0.0122$ for G; Co + Co, ANOVA). No difference is seen in the density of GFAP-like and laminin immunoreactivity within the three groups (ANOVA).

analysis showed no significant difference between the two groups regarding graft volumes. The study of TH-positive nerve fiber densities of the intraocular double grafts six weeks after grafting revealed no significant difference between the gluetreated and the untreated groups. Likewise, GFAP and laminin immunoreactivity also appeared similar. Since TH-positive fibers found in the locus coeruleus plus cortex cerebri grafts could not be derived from the sympathectomized iris, their presence in the cortex part of the double graft proves that a coeruleo-cortical TH-positive pathway had formed. Clearly, the fibrin glue did not interfere with the growth of nerve fibers; nor did it cause any untoward gliosis or disturbed microcirculation in the grafts.
Study of the ultrastructure of fibrin glue with confocal laser 3D microscopy, liquid permeation and turbidity $/ 5 /$ shows that the glue from normal fibrinogen is composed of straight rod-like fiber elements which sometimes originate from denser nodes. The tautness and porosity of the glue networks can be altered by changing the concentration of thrombin and fibrinogen. Thus increasing either thrombin or fibrinogen concentrations will cause the glue networks to become tighter and the porosity to be decreased. The fiber strands also become shorter. Glue porosity of the network can also be modified by changing the ionic strengths, coexisting proteins (e.g. albumin, lipoprotein), dextran, etc.

For the catecholaminergic cells in the locus coeruleus graft to survive and grow, nutrients and diffusible factors (such as trophic factors, from either the iris or the co-grafted cortical piece) must be able to reach the cells in the graft /18-21/. The endothelial cells from the iris must also have access to the graft, otherwise the graft would degenerate and die. The present study supports the finding that nutrients and trophic factors can pass through the fibrin glue networks to reach the graft. It means, with the present formula, the formed fibrin polymers create a mesh that will hold two graft pieces together but also permit the transmission of essential molecules through its pores. The endothelial cells from the iris can penetrate the fibrin meshwork around the graft and finally establish the microvasculature. Likewise, TH-positive fibers from the locus coeruleus can also penetrate the fibrin glue in between the two grafts and reach the cortical piece. The fibrin meshwork is known to be absorbed by the fibrinolytic system (e.g. plasmin) one week after application. The feasibility for the lysis of fibrin glue can also be altered by structural modification of the extended dimeric multidomained fibrin molecule (e.g. as shown in the studies of Blombick et al. and Nossel \& Kaplan $/ 5,17 /$, a scheme involving fibrin I and fibrin II, in which the former is the result of releasing the fibrinopeptide only. Fibrin II lacks both fibrinopeptides A and B and is thought to be involved in lateral anchoring; as a consequence it is more resistant to fibrinolysis), presence of physiological stabilizing factor XIIIa, interactions between plasminogen, thrombin and fibrin, cross-linked fibronectin in the tissues, platelets, etc. $15,7,17,25 /$. 
In the anterior chamber of the eye, the fibrin glue is exposed to the chamber fluid, the iris, locus coeruleus and cortical graft. Since there was no significant difference in graft growth or final sizes between glue-treated and control double grafts, it appears as if the glue coat did not significantly impair the rate of formation or amount of vascular connections between host iris and grafts. The lysis of the glue will be affected by numerous factors and interactions. The timing of the penetration of endothelial cells and neurites, in relation to fibrinolysis, remains to be further analyzed.

\section{ACKNOWLEDGEMENTS}

The Beriplast ${ }^{\oplus} \mathbf{P}$ fibrin glue was kindly supplied by Behringwerke AG, Germany. The study was supported by the Swedish Medical Research Council 03185, USPHS grants NS09199 and AG04418, Taiwan Chin-Lin Medical Research Fund and NSC77-0412-B075-17.

\section{REFERENCES}

1. Becker CM, Guenuning CO, Graff GL. Sutures or fibrin glue for divided rat nerves: Schwann cell and muscle metabolism. Microsurgery 1985; 6: 1-10.

2. Bento RF, Miniti A. Comparison between fibrin tissue adhesive, epineural suture and natural union in infratemporal facial nerve of cats. Acta Oto-Laryngol Suppl 1989; 465: 1-36.

3. Bertelli J, Mira J. Nerve repair using freezing and fibrin glue: immediate histologic improvement of axonal coaptation. Microsurgery 1993; 14: 135-140.

4. Björklund H, Olson L, Seiger $\AA$, Hoffer B. Chronic lead and brain development: intraocular brain grafts as a method to reveal regional and temporal effects in the central nervous system. Environ Res 1980; 22: 224236.

5. Blombäck B, Banerjee D, Carlsson K, Hamsten A, Hessel B, Procyk R, Silverira A, Zacharski L. Native fibrin gel network and factors influencing their formation in health and disease. In: Liu CY, eds. Fibrinogen, Thrombosis, Coagulation, and Fibrinolysis. New York and London: Plenum Press, 1990: 123.

6. Cruz N, Debs N, Fiol R. Evaluation of fibrin glue in rat sciatic nerve repairs. Plastic \& Recons Surg 1986; 78: 369-373.

7. Doolittle RF. Fibrinogen and fibrin. Ann Rev Biochem 1984; 53: 195-229.

8. Egloff D, Narakas A. Nerve anastomoses with human fibrin. Annales de Chirurgie de la Main 1983; 2: 101115.

9. Herter T. Electrophysiologic comparison between sutured and glued anastomosis. Unfallchirurg 1989; 92: 560-563.

10. Maragh H, Meyer B, Davenport D, Gould J, Terzis J. Morphofunctional evaluation of fibrin glue versus microsuture nerve repairs. J Recons Microsurgery 1990; 6: 331-337.

11. Matras H, Dinges H, Mamoli B. Non-sutured transplantation: a report on animal experiments. J Maxillofac Surg 1973; 1: 37-40.

12. Matras H. Fibrin seal: the state of the art. J Oral Maxillofac Surg 1985; 43: 605-611.

13. Medders G, Mattox DE, Lyles A. Effects of fibrin glue on rat facial nerve regeneration. Otolaryngol Head Neck Surg 1989; 100: 106-109.

14. Moy O, Peimer C, Koniuch M. Fibrin seal adhesive versus nonabsorbable microsuture in peripheral nerve repair. J Hand Surg 1988; 13A: 273-278.

15. Narakas A. The use of fibrin glue in repair of peripheral nerves. Orthop Clin N Am 1988; 19; 187199.

16. Nishihira S, McCaffrey TV. Repair of motor nerve defects: Comparison of suture and fibrin adhesive techniques. Otolaryngol Head Neck Surg 1989; 100: 17-21.

17. Nossel HL, Kaplan KL. Fibrin. In: Bing D, ed. Chemistry and Physiology of the Human Plasma Protein. New York: Pergamon, 1979: 97-110.

18. Olson L, Seiger $\AA$, Fuxe K. Isolated catecholaminergic projections from substantia nigra and locus coeruleus to caudate hippocampus and cerebral cortex formed by intraocular sequential double brain grafts. Exp Brain Res 1972; 36: 47-67.

19. Olson L, Seiger $\AA$. Brain tissue transplantation to the anterior chamber of the eye. I. Fluorescence histochemistry of immature catecholamine and 5-HT neurons reinnervating the rat iris. $Z$ Zellforsch 1972; 135: $175-194$.

20. Olson L, Seiger $\AA$, Strömberg I. Intraocular transplantation in rodents. A detailed account of the procedure and examples of its use in neurobiology with special reference to brain tissue grafting. In: Federoff $\mathrm{S}$, Hertz L, eds. Advances in Cellular Neurobiology. New York: Plenum, 1983; 4: 407-442.

21. Olson L. Grafting in the mammalian central nervous system: Basic science with clinical promise. In: Magistretti P, ed. Discussions in Neurosciences. Geneva: FESN, 1988; 1-73.

22. Romano V, Blair S, Kerns J, Wurster R. Comparison of fibrin glue, bioresorbable tubing and sutures in peripheral nerve repair. Restor Neuro \& Neurosci 1991; 3: 75-80

23. Rossitch EJ, Wilkins R. The use of fibrin glue in neurosurgery. In: Wilkins RH, Rengachary SS, eds. 
Neurosurgery Update I. New York: McGraw-Hill, 1990: 195-196.

24. Seddon HJ, Medawar PB. Fibrin suture of human nerves. Lancet 1942; 2: 87-89.

25. Sladek JJ, Gash DM. Neural Transplants: Development and Function. New York: Plenum Press, 1984.

26. Smahel J, Meyer V, Bachem U. Glueing of peripheral nerves with fibrin: experimental studies. J Recons Microsurg 1987; 3: 211-219.

27. Wigand $M$, Thumfart $W$. Neurosynthesis of the facial nerve: electrical vs. clinical results. In: Samii $M$, Jannetta PJ, eds. The Cranial Nerves: Anatomy, Pathology, Pathophysiology, Diagnosis, Treatment. Berlin: Springer-Verlag, 1981: 463-468.

28. Young JZ, Medawar PB. Fibrin suture of peripheral nerve. Lancet 1940; 2: 128. 

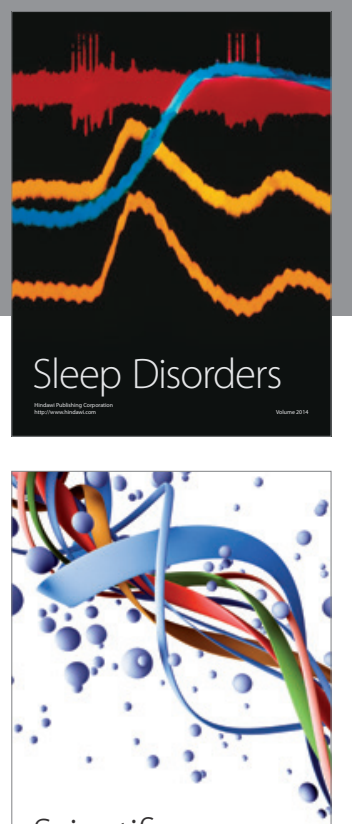

Scientifica
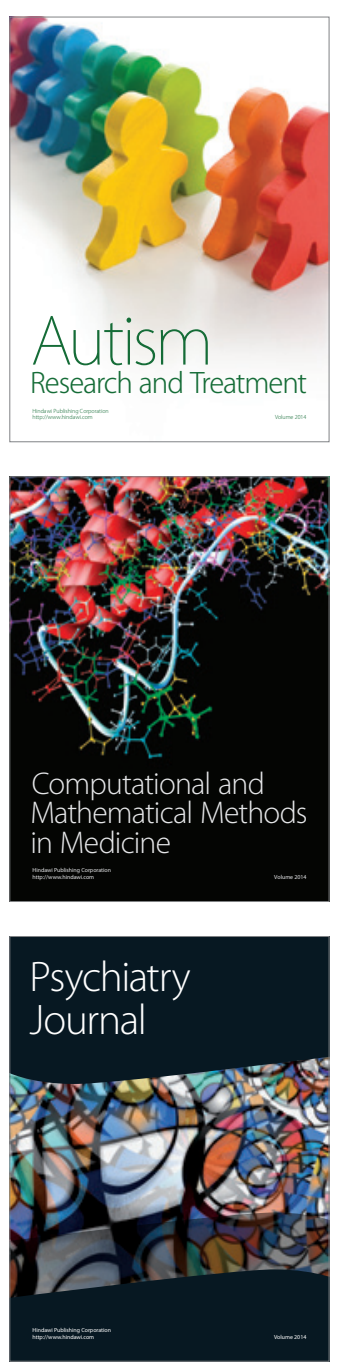
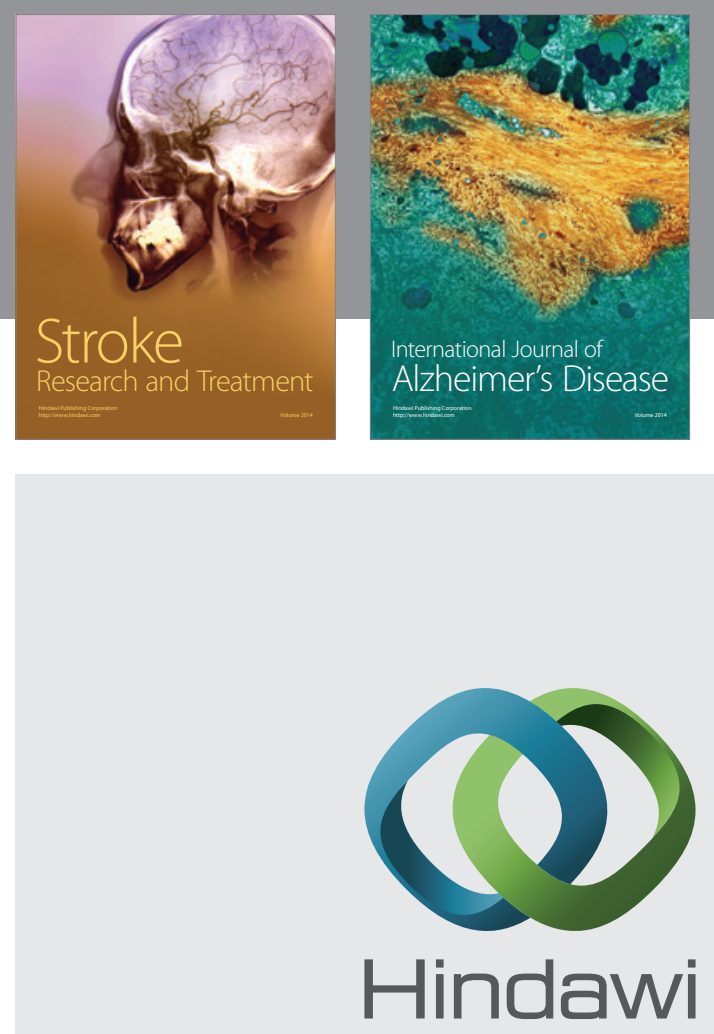

Submit your manuscripts at

http://www.hindawi.com
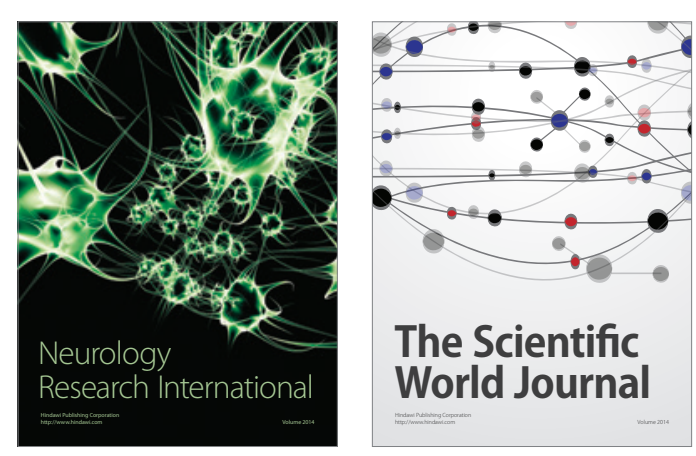

The Scientific World Journal

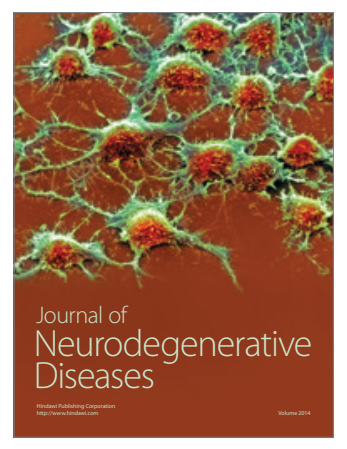

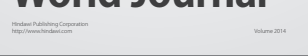

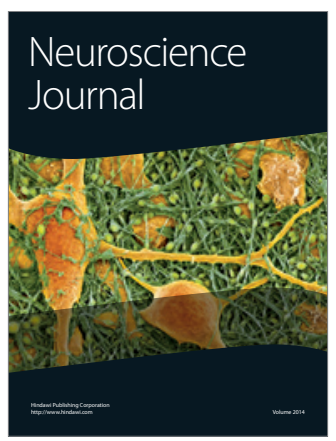

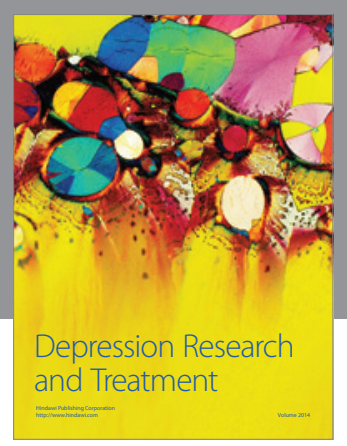
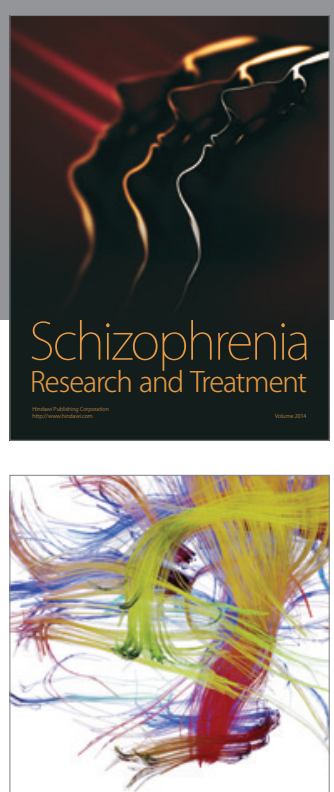

Brain Science

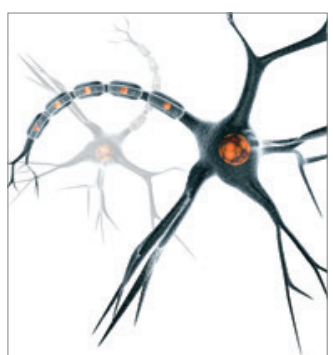

Neural Plasticity
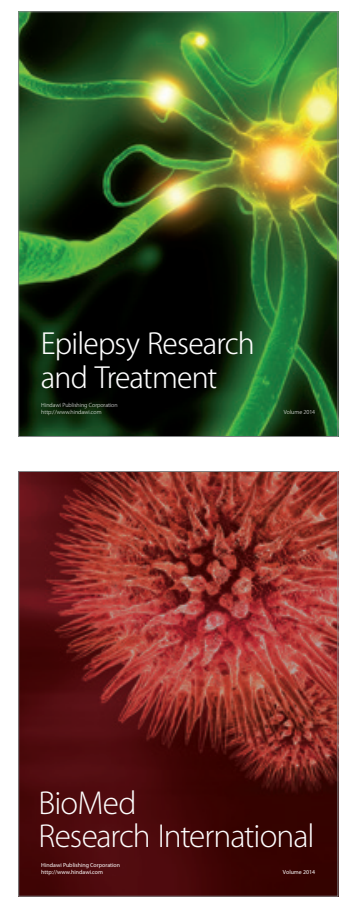

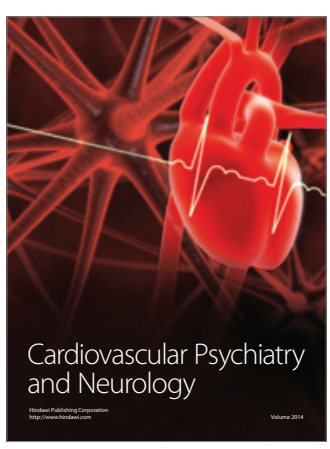

Parkinson's

Disease
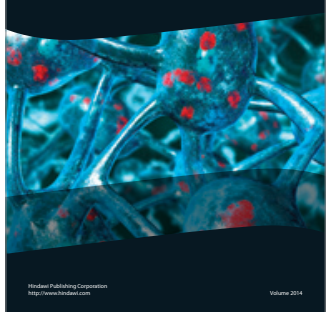